\title{
AUTORIDAD Y DEMOCRACIA EN LA CULTURA POPULAR
}

Una aproximación desde la cultura andina

\author{
Juan Ansión
}

EL PRESENTE TEXTO es un primer balance de una reflexión de muchos años que parte desde la sierra ayacuchana y busca entroncarse con el país mirándolo a la luz de las grandes experiencias populares de las últimas décadas. El reto es pensar al país desde lo popular y pensar lo popular desde sus raíces andinas.

Son reflexiones inconclusas, pues son un nuevo punto de partida para una investigación sobre cultura política popular en Lima (1). Por ello, deben leerse como hipótesis orientadoras, como sugerencias para la investigación.

\section{1 - Continuidad y ruptura}

La cultura política popular, estudiada en relación con la historia del movimiento popular en el país, aparece como el producto de varios milenios a la vez que de las profundas transformaciones de las últimas décadas: como fruto de la tradición andina y también de la modernidad. 
Es desde esta perspectiva de continuidad y ruptura que me interesa enfocar el modo actual de hacer política en los sectores populares. Parecen en efecto insuficientes y unilaterales las aproximaciones que lo reducen todo a uno solo de los dos aspectos.

En un caso, se desconoce en efecto la originalidad de las relaciones sociales nácidas del mundo moderno, vinculadas a la difusión de las relaciones mercantiles y de las formas de producción propias del capitalismo. De manera arbitraria se reduce la realidad social actual a una simple continuación del conflicto entre el mundo andino y el mundo occidental. Se supone además implícitamente -dentro de un enfoque ya criticado hace más de dos décadas por los teóricos de la dependencia- que nuestra sociedad es básicamente dual, entendiéndose la relación entre lo tradicional y lo moderno como una relación entre los supuestos sectores sociales atrasados y los sectores considerados adelantados. Una consecuencia de este dualismo es que se supone que existen dos países que se ignoran mutuamente y que el problema del Perú se reduce al malentendido cultural. Más allá de los matices, ésta parece por ejemplo haber sido la visión que predominó en la Comisión que investigó los sucesos de Uchuraccay.

Esta remozada perspectiva dualista se expresa en formas de indianismo o de neoindigenismo más o menos manifiestos en diversos trabajos y estudios de los últimos años sobre el mundo andino. Es una óptica que toma en cuenta una situación real de dominación social que combina la explotación económica con múltiples formas de discriminación por rasgos étnicos y color de la piel, pero que tiende a menudo a suponer una fuerza propia de la cultura, como si fuera independiente de los procesos históricos y de las necesidades materiales. De ello resulta una no deseada aunque objetiva coincidencia de la búsqueda sincera de revaloración de la cultura andina, entendida 
como cultura separada, con la vieja actitud de desprecio por la cultura andina considerada inferior $y$ propia de "salvajes".

El segundo caso es mucho más conocido y enraizado. Es la creencia de que la modernidad o la tecnología, o aun la sociedad capitalista, viene arrasando de manera decisiva toda la tradición. Se reconocen eventuales "rezagos" o "supervivencias", pero se cree que éstos están condenados a perecer puesto que ya no tendrían mayor importancia ante el proceso de "desandinización" en marcha. Este punto de vista también es apresurado y desconoce los complicados $\mathrm{y}$ diferenciados procesos de transformación cultural que se vienen produciendo en el Perú de hoy, que no encuentran explicación posible sin tomar en cuenta la base andina que les da origen.

Aunque cada uno de estos puntos de vista resulta equivocado si se toma de manera unilateral, tomados juntos expresan los dos aspectos en pugna de la tensión fundamental entre continuidad y ruptura. Ante las situaciones históricas nuevas que tienen que enfrentar, los hombres reproducen viejas prácticas, las renuevan, o inventan otras nuevas. Lo hacen para responder a retos concretos, pero también recurren en primer término al bagaje cultural heredado a partir del cual reproducen las antiguas soluciones o inventan otras nuevas. Es posible, como sucede hoy en día, que no se tenga conciencia de la tradición de la cual se es tributario, e incluso que se la rechace explícitamente, pero ello no quiere decir que realmente se logre ese propósito en todos sus aspectos. De lo contrario, los hábitos culturales más eficaces suelen ser los menos aparentes y por ello los más difíciles de negar conscientemente (ello no significa, desde luego, desconocer que el rechazo abierto de la propia tradición cultural, tenga efectos sociales importantes). 
Buscando superar las dos visiones parciales de la realidad, habrá entonces que ir precisando, en el campo de la cultura política popular, de qué manera, en las nuevas circunstancias históricas urbanas, el pueblo viene pugnando por acceder a la modernidad desde su tradición, considerada ésta como un telón de fondo que sigue muy vivo.

\section{2 - Lo nuevo y lo antiguo en la cultura política popular}

Para estudiar la cultura política popular en la actualidad, resulta entonces fundamental relacionar las nuevas formas de hacer política y de concebirla, con la antigua cultura política andina que sigue siendo una de las claves para entender la realidad actual. No significa, como queda ahora claro, reducirlo todo a las raíces andinas. Debe tomarse en serio lo realmente nuevo, como elemento de ruptura: básicamente la experiencia popular urbana desde la cual se ha venido desarrollando, en los últimos decenios, una cultura política con respuestas originales a los múltiples retos del mundo moderno.

A su vez, es necesario insistir en las bases andinas de nuestra cultura política popular porque son masivamente ignoradas o negadas. Al no haber sido resuelto en términos sociales y culturales el viejo trauma de la Conquista, se hace difícil una necesaria ruptura con el pasado que se apoye en un reconocimiento de que ese es el pasado del que se proviene.

Los sectores populares urbanos integrados a la vida "moderna", se orientan así hacia lo moderno y desean el "progreso" sin que hayan terminado de asumir la antigua herencia colonial que asentó la sociedad peruana sobre la base de la violencia y la discriminación. 
Es entonces importante trabajar desde lo que se sabe de lo político en el mundo andino, como un paso imprescindible para evaluar el proceso cultural actual, y considerar las antiguas tendencias y tensiones que siguen actuando con fuerza en la actualidad, aun cuando los actores no tengan conciencia clara de ellas. No se trata de explicar todo el presente por el pasado, sino de ver cómo en el sistema social actual se siguen utilizando hábitos y modos de pensar antiguos, que se redefinen y transforman en respuesta a retos totalmente nuevos y en contacto con ideologías y prácticas nacidas del mundo moderno.

\section{3 - Lo político como resolución de conflictos}

En el debate sobre la cultura andina, es importante evitar toda interpretación metafísica que busque la "esencia de lo andino". Dicho esto, sostengo que las sociedades andinas han ido creando a lo largo de su historia configuraciones culturales que, dentro de una natural heterogeneidad, han desarrollado importantes rasgos comunes (entre ellos un modo particular de pensar y de organizar la realidad de acuerdo al padrón de cuatripartición). Para avanzar en esta discusión - y evitar los debates ociosos que contraponen simples opiniones- debemos seguir investigando para conocer mejor la realidad social y cultural que convenimos en llamar andina, para poder así debatir con argumentos sustentados en hechos. Valgan por ello las presentes reflexiones como pistas para investigar la realidad cultural andina en uno de sus aspectos fundamentales: su modo de hacer política.

Para estudiar la cultura política en la sociedad andina, vamos a considerar lo político como el espacio de resolución de conflictos sociales (2). En la sociedad andina, observamos distintas formas de resolver los conflictos entre 
los grupos constitutivos de la sociedad (desde los conflictos entre grupos domésticos, unidades sociales mínimas, hasta entre los grupos étnicos y entre las macroetnias). Esta resolución puede ir desde el enfrentamiento violento hasta el logro del acuerdo mediante la discusión ordenada entre las partes. Entre ambos extremos se ubica una forma muy interesante: la ritualización del conflicto mediante formas reguladas de enfrentamiento, a modo de competencia.

Se conoce de enfrentamientos violentos entre comunidades, ligados a litigios ancestrales por tierras. Es probable sin embargo que la lucha abierta y directa no represente sino una manera excepcional de resolver conflictos, y que su realización dependa de las circunstancias históricas externas.

Sobre la resolución mediante el diálogo, mucho está por investigarse. Ciertamente que éste es un método utilizado dentro de las familias para superar pleitos domésticos recurriendo al arbitraje de padrinos o de autoridades comunales. Pero éste es también el método principal para la organización de las actividades comunales. Así por ejemplo, el estudio reciente de Ricardo Valderrama y Carmen Escalante (3) sobre el pueblo de Yanque, en el valle del Colca (Arequipa) muestra cómo el reparto anual de las aguas es producto de un intenso debate entre los comuneros. En esta discusión -rimanakuy en quechua- afloran los intereses contrapuestos de los regantes, que tienen sin embargo la necesidad vital de ponerse de acuerdo. Se llega finalmente a un compromiso que todos se comprometen a respetar. El regidor de aguas (yaku alcalde) es el encargado de hacer cumplir el acuerdo.

La pelea ritual es otra forma de resolver conflictos. Aquí, las partes no llegan a ningún acuerdo verbal, pero tampoco están dispuestas a hacerse la guerra, porque, aunque se sientan contrapuestas, se necesitan mutuamente 
(como sucede por ejemplo en muchos sitios entre los de la puna y los del valle, o entre el barrio de arriba y el barrio de abajo). El concepto andino de este encuentro con competencia es el de tinkuy. Steve Stern nos dice al respecto (4):

"Un aspecto de un encuentro tincu era la competición, una tentativa de sacarle ventaja a la otra parte. Tincuni significaba encontrarse para combatir (...) Pero el otro aspecto de los puntos de encuentro tincu era el de la cooperación, la igualdad, el ajuste. (...) El concepto tincu de lo justo o lo perfecto se refería al emparejamineto necesario de entidades distintas en relaciones idealmente equivalentes, pero a menudo conflictivas, a fin de lograr una unidad mayor".

No se elimina el conflicto, se lo canaliza, reduciéndolo en forma ritual a un ámbito limitado y controlado de competencia. Lo mismo observan Vergara y Vásquez en su estudio del carnaval ayacuchano (5), cuando nos hacen ver cómo las comparsas de carnaval, constituídas sobre la base de la familia y del barrio, afirman su propia identidad en la competencia. En el carnaval campesino, según los mismos autores, se realizan competencias de pulseo (levantar piedras grandes) o de lucheo (forma de lucha entre dos jóvenes).

"En algunas comunidades de Huamanga, y también de Vilcashuamán, en el Siqullunakuy se utiliza látigos o Warakas con las que se azotan los contrincantes. Por turno se levantan las mangas de los pantalones hasta la rodilla y resisten los azotes, sin dar muestras de dolor, muchas veces hasta sangrar'. (Vásquez, Vergara: 41). 
En este último caso, queda claro que el combate ritual que permite superar el conflicto es al mismo tiempo un tipo de sacrificio, pues es posible que la sangre que corre sea percibida como ofrenda a la tierra.

Asimismo, aparece la relación con los encuentros deportivos. Es posible que el fútbol siga cumpliendo en la actualidad una función similar, pues es notorio el entusiasmo por ese deporte, siendo el campo de fútbol el único terreno plano (o casi plano) en todos los pueblos y comunidades de la sierra.

De modo general, la cultura andina parece haber enfatizado ese aspecto de competencia en muchos niveles, como forma de construir y reproducir lo social. Recordemos también en ese sentido las justas verbales llenas de humor, el contrapunteo en las canciones, las competencias en el baile y en especial las de los danzantes de tijeras. Todas estas formas tienden, a través de un ambiente festivo, a reducir el conflicto y tratarlo en una suerte de microcosmos de acuerdo a normas conocidas y respetadas por todos.

\section{4 - La relación de autoridad en el mundo andino}

Desde el Ensayo sobre el don de Marcel Mauss, sabemos que la autoridad en las sociedades no estatales, se deriva de la capacidad de dar. Es poderoso quien "aplasta" al otro con su generosidad. Pese a la presencia del Estado, este principio ha seguido siendo válido para el campesino andino. Como se sabe, para obtener prestigio y autoridad en la comunidad, es preciso "pasar cargos", lo que supone siempre demostrar una gran generosidad.

La autoridad resulta de esa generosidad, y también de la convicción compartida por todos de que el dirigente está cumpliendo un servicio a la comunidad. 
En el ayllu y en la comunidad tradicional, la autoridad es la voz de todos. El que habla como dirigente, en el tiempo que le toca cumplir su cargo, no sólo lo hace $a$ nombre de todos, sino desde el punto de vista de los andinos, es verdaderamente la voz única del conjunto (aunque en realidad la identidad no parece nunca ser total).

Al mismo tiempo, el dirigente está refrendado por una autoridad sagrada, la del Padre Cerro que lo reconoce mdiante el ritual con el que se inicia el nuevo cargo. Del mismo modo como existe una identificación entre el dirigente y el conjunto, así también se produce una identificación entre el dirigente y el Cerro o la entidad divina protectora.

Esta doble identificación aparece con bastante claridad en un relato analizado en un trabajo anterior (6), en el que el varayuq de Huamanquiquia (Ayacucho) llega a fusionarse con el Cerro Pirwachu, protector de la comunidad, a la vez que no actúa para "reivindicar a la comunidad" sin antes haber reunido a todos y logrado su aprobación.

La autoridad del dirigente parece así apoyarse en el reconocimiento por todos de esta doble identificación que lo convierte en un verdadero intermediario con el garante sagrado. $\mathrm{Y}$ al mismo tiempo, como se ha visto también en el caso de Yanque, a nivel social su autoridad se apoya en el consenso nacido de la discusión libre entre todos (rimanakuy).

La contraparte de ese principio democrático, es el poder fuerte del que manda, y que es la voz de todos, Aun así, existen mecanismos de control. Ya hemos visto que el sistema de cargos impide grandes niveles de acumulación personal, pero ésta no es la única forma de control. Así, en Yanque, el regidor de aguas, que tiene toda la autoridad para hacer cumplir de manera drástica los acuerdos, es acompañado por un yana, un ayudante, que le es for- 


\section{Juan Ansión}

malmente subordinado, pero que en la práctica tiene mucho poder porque es el especialista que sabe cómo dirigirse al Cerro.

\section{5 - Transformación de la relación de poder}

Al entregar toda la autoridad a una persona, así sea por un tiempo limitado y generando mecanismos de control, la comunidad corre un riesgo constante: el que esa persona abuse de su poder y lo ejerza a favor de un solo sector de la población. Significa que siempre es posible que la sociedad pierda el control sobre la autoridad que instituyó. Esto ocurre de hecho cuando el jefe recibe más de lo que da, invirtiendo así la lógica del poder emanado del don.

Está aquí en germen el poder fuerte de los estados andinos, que suponen estratificación social desarrollada y deificación del jefe (curaca a nivel de macroetnia, e Inca como cabeza del Estado imperial). La deificación está ligada a la identificación (total, desde el punto de vista de la ideología estatal) del jefe con la entidad sagrada (Huiracocha y el Sol en el caso Inca) y a su papel de mediador con el pueblo con el que se produce también esa identificación ideológica.

En el mundo andino, este proceso parece claramente ligado a la lógica guerrera, como en el caso de los Mochicas, Huaris, Chancas e Incas.

La situación se hace más compleja con la Conquista, a partir de la cual se descabezan las autoridades andinas, siendo reemplazadas por españoles. La relación con el poder - salvo con el poder interno al grupo familiar en el ayllu y la comunidad- se vuelve muy ambivalente: sumisión aparente y rebeldía latente. De algún modo la sociedad andina se acomoda de los nuevos caudillos -sean és- 
tos blancos o no- porque le han sido impuestos por la fuerza, pero también porque reproducen formas tradicionales y conocidas de dominación. Pero este "acomodo" está también en tensión con otra tendencia tradicional de la sociedad andina: su milenaria voluntad de buscar resolver los conflictos de intereses mediante acuerdos entre las partes.

\section{6 - Las relaciones de parentesco y lo político}

Examinemos ahora el problema del poder colocándonos desde el punto de vista de los grupos de parentesco, que constituyen la base de la organización social en una sociedad tradicional como la andina.

La sociedad andina mantiene una enorme tensión entre una tendencia a la endogamia y su necesidad de alianza entre grupos (tendencia a la exogamia). Esta contradicción se relaciona con la estrategia de los "archipiélagos" estudiada por John Murra: el grupo familiar busca ocupar la mayor cantidad de pisos ecológicos, de manera a obtener la mayor diversidad de productos por autosostenimiento y no depender del intercambio con otros grupos. En esta situación, los colonos que se han desplazado a otros pisos ecológicos, viven lejos de muchos de sus familiares y cerca de extraños que se han establecido a proximidad respondiendo a una lógica similar. Con estos últimos, si no se quiere estar en guerra contínua se tienen que establecer relaciones que permitan la convivencia. Muchos antiguos combates rituales, de los que hemos hablado ya, pueden haber respondido a una necesidad de este tipo.

En la lucha política también debió manifestarse esta tensión muy fuerte entre lo endogámico y lo exogámico. María Rostworowski (7) muestra por ejemplo cómo entre los incas, a partir de la expansión estatal (probablemente 
desde Pachacutec) se desarrolló una tendencia de las panacas (familias del Cusco a consolidarse internamente evitando las alianzas, lo que es una explicación plausible del incesto del Inca con su hermana (que más que hermana en sentido estricto debió ser una prima paralela, es decir una mujer que pertenecía a su propia panaca). Al encerrarse en sí mismas las panacas se habrían entonces constituido en herramientas de poder muy fuertes, algo así como los partidos políticos de aquella época, pero su debilidad fue entonces que todas las demás se convertían en sus enemigos si se descuidaba establecer con ellas las tradicionales alianzas matrimoniales (y por ende también políticas). La tendencia contraria, que privilegia la alianza entre grupos, la encontramos por ejemplo en la dualidad andina del poder, también estudiada por María Rostworowski (8), que significa que el poder es ejercido por dos jefes, representantes de dos partes sociales claramente separadas, pero reunidas para combatir a un común enemigo.

Formulo la hipótesis de que la predominancia de la tendencia a la endogamia, al repliegue en sí mismo, corresponde a una estrategia en términos autoritarios, agresivos, guerreros, basada en una fuerte jerarquización (del tipo: “ ¡disciplina, compañeros!"), mientras la tendencia a la exogamia supone el ponerse de acuerdo, el buscar formas de consenso y de alianza entre pares. Lo primero conduce más rápidamente a la unidad pero tiene también bases más débiles a la larga, porque corresponde a un poder que tiene menor legitimidad y tiene que imponerse más como dominación. Es interesante anotar que en el caso de la India también, según Louis Dumont, el principio de jerarquía es un complemento necesario del carácter endogámico de las castas.

Por otro lado, cabe precisar que estos términos son relativos. Entre dos barrios de un pueblo, pueden existir alianzas matrimoniales, siendo por ende exogámicas las 
relaciones entre ellos. Pero si quienes viven en estos barrios no se casan con los hijos o hijas de otros pueblos, existe endogamia si se considera al pueblo en su conjunto. Lo que a nosotros aquí nos importa es el uso político de esta tensión social entre dos tendencias.

La tendencia a encerrarse está ligada al espíritu de castas, en su sentido más estricto. Louis Dumont (9) observa la relación en la India entre el sistema social de las castas y una ideología centrada en la noción de pureza. Es posible que algo similar se dé en el caso peruano. En términos políticos, el militante "puro y duro" es el ideal de esta perspectiva. La moral es de entrega total, sin concesiones al enemigo (es decir a todos los demás grupos políticos), sin concesiones tampoco al placer. Es la moral ascética del guerrero espartano. Se contrapone al pragmatismo popular -y especialmente campesino-- pero al mismo tiempo ejerce sobre él una gran fascinación porque el campesino se siente culpable de mil cosas, se siente impuro y puede llegar a admirar la entrega total de quienes pretenden purificar el mundo en un incendio regenerador. Eso está ligado a la noción de sacrificio, muy difundida en la cultura popular de hoy.

A esta tendencia se liga la fascinación por las armas que tienen un verdadero carácter mágico, semejante al del papel escrito y del libro en la tradición andina colonial. Esto es especialmente cierto entre los más jóvenes. Es la fascinación de "ser alguien", de ser temido y respetado (mientras los jóvenes, tanto en la sociedad urbana como en la rural, no han sido escuchados, y enfrentan graves problemas de inserción social y laboral).

La tensión entre lo endogámico y lo exogámico es, desde luego, un fenómeno universal. Sólo hemos querido señalar que en la sociedad andina esta tensión ha sido un elemento central de articulación social y de transformación, en torno al cual han girado las estrategias políticas, de busca de alianzas o de enfrentamientos. 


\section{7 - Para estudiar lo popular desde lo andino}

Nos interesan las dos grandes tensiones analizadas en la sociedad andina (entre poder vertical y búsqueda del consenso; y entre endogamia y exogamia) para ver de qué manera nos permiten entender mejor la vida política actual. ¿Cómo la tensión entre una autoridad de consenso y una autoridad de dominación se manifiesta hoy día en la izquierda peruana? ¿Cómo también la contradicción entre lo endogámico y lo exogámico se reproduce entre fuerzas políticas, grupos sindicales, organizaciones vecinales, etc., como tendencias hacia lo endógeno o hacia lo exógeno, hacia poner por delante el refugio en sí mismo o hacia la priorización de la alianza? Esta tensión ya no necesariamente se expresa en términos de alianza matrimonial, aunque los vínculos de parentesco sigan siendo importantes en política, y más aún, las relaciones sociales se viven en buena medida sobre el modo de la vida de la familia (por ejemplo, el partido es considerado como una familia).

En la relación con el jefe, se presenta fácilmente la identificación con la persona, en la relación tradicional de poder. En la política moderna, esta práctica choca con la conformación de organizaciones políticas que pongan por delante, como base de su unidad, una ideología y un programa. La resolución del asunto se da, en partidos como el Apra o Sendero Luminoso, mediante la identificación de la ideología y del programa con el líder. Esta práctica va ligada a una tendencia hacia lo endógeno y el verticalismo.

En la perspectiva exógena, el jefe es mediador, su poder se origina en el consenso, pero luego es un poder muy fuerte que impone a todos el consenso logrado. Al convertirse por un tiempo en la voz del pueblo, el jefe parece verdaderamente ser el pueblo, pero en el mismo acto 
se pone aparte del pueblo. Este proceso ha sido estudiado por la antropología política. Así, Pierre Clastres sostiene que la sociedad primitiva rechaza activamente la separación del jefe para con la sociedad, que al darle poder se lo limita al mismo tiempo. En la sociedad andina, lo hemos visto, existen mecanismos para controlar este poder que se aparta de la sociedad: rotación del cargo (aun cuando, en general, mediante el cargo se adquiere mayor prestigio que da también poder), redistribución mediante contribuciones de quienes pasan los cargos.

En la práctica política de la izquierda, los partidos parecen caracterizarse por la práctica endógena, mientras los gremios lo serían más por la práctica exógena que busca el consenso entre diferentes grupos de interés de los agremiados (sindicalistas, pobladores, comuneros, etc.). En la actualidad, algunos gremios se ven obligados inclusive, en el modo de reclamar al Estado, a tomar en cuenta las demandas de los beneficiarios de su actividad (los trabajadores de salud frente a los enfermos, los profesores frente a los educandos).

El Frente político es más próximo, en este sentido de la organización gremial, pero tiene una gran dificultad: mientras para el gremio, el consenso es relativamente fácil de lograr, porque los objetivos son limitados a reivindicaciones muy concretas, en el nivel político los acuerdos a tomarse comprometen objetivos de largo alcance, visiones de la sociedad. En este sentido, un gremio manipulado por un partido puede funcionar mal que bien, cosa mucho más difícil en un frente político. Es presumible que el tipo de liderazgo que sea muy reconocido en el gremio será también el que tendrá éxito en el frente político, donde tendrá que afirmarse con más fuerza para tener éxito. Se trata de un liderazgo de creación de consenso más que de imposición de una línea prefijada. 


\section{Juan Ansión}

A nivel urbano, la pregunta clave es: ¿Cuándo un dirigente sindical o barrial es considerado bueno? Se supone que es un buen mediador entre los miembros de la organización, pero afirmar esto no iosta, pues la pregunta siguiente, en todo caso, sería: ¿Qué debe hacer un dirigente sindical o barrial para ser un ,ouen mediador entre los asociados? $\mathrm{Y}$, en especial: ¿De qué manera logra superar los conflictos dentro del gremio?

Si suponemos que existe contraposición entre la lógica exógena del gremio y la lógica endógena del partido, un dirigente de organización popular, que es también militante de un partido, se encuentra necesariamente en una gran contradicción, la que puede desembocar en las siguientes soluciones:

1) Prevalece la lógica del partido. En este caso, el dirigente impone una línea sectaria en el gremio. Si existen varios partidos, se corre el riesgo del paralelismo gremial. En todo caso, se presentan enfrentamientos muy duros que se originan en las relaciones interpartidarias antes que en problemas propiamente gremiales.

2) Prevalece la lógica exclusivamente gremial. En este caso, se logra consolidar un frente de lucha a propósito de las reivindicaciones concretas, sin mayores posibilidades de darles un contenido político.

3) El partido aprende en la lucha gremial y logra un trabajo de frente también en el nivel político: es la situación más favorable (se resuelve la tensión entre situación (1) y situación (2).

4) Se mantiene el divorcio entre gremio y partido, sin que prevalezca con nitidez ninguno de los dos (se dan 
las situaciones (1) y (2) a la vez, sin que ninguna de las dos logre vencer). El resultado es una lucha muy fuerte dentro del gremio entre gremialistas antipartido y militantes de partido.

5) Se combina la situación (3) con la (4): algunos partidos entran en un trabajo de frente, mientras otro(s) mantiene(n) en el frente la misma lógica que la del partido dentro del gremio.

Estas cinco situaciones pueden aparecer en algún momento de la historia de cualquier gremio. En cada caso, es importante analizar el proceso histórico, ver de qué manera se resuelven las contradicciones $\mathrm{y}$, dentro de ese contexto, estudiar de qué manera actúan y se expresan los participantes, especialmente los dirigentes.

\section{8 - Perspectivas}

En la cultura popular, la lógica de ruptura, propia de la perspectiva endógena, se ha venido redefiniendo en la búsqueda de la unidad de los sectores populares, por oposición al gobierno y a los representantes de las clases dominantes. Pero al mismo tiempo, el carácter segmentado de la sociedad ha hecho difícil esta unidad dentro del pueblo. El Apra logró en ese sentido importantes avances en los años 30, pero fue a costa del abandono de una alianza muy amplia de sectores populares y de una ruptura radical con toda forma de comunismo, privilegiando en cambio, posteriormente, su alianza con los representantes de la vieja oligarquía. Sendero Luminoso, por su parte, representa la opción más nítida de ruptura total y de repliegue en lo endógeno, ruptura que se da tanto con el Estado como todos los demás partidos políticos, conside- 
rados todos como cómplices de la dominación y de la explotación del pueblo.

En las luchas populares de los años 70, sin embargo, se fueron desarrollando nuevas perspectivas que criticaron en la práctica el sindicalismo aprista que había perdido su independencia frente a los sectores patronales, y tomaron también distancia de los intentos del gobierno militar de Velasco por organizar al movimiento popular bajo la tutela del Estado. Surgieron entonces grandes Movimientos de lucha, con nuevos dirigentes populares que criticaban al "amarillaje" (la subordinación a los patrones) y al "corporativismo" del Estado, a nombre del clasismo, es decir de la autonomía de las clases populares en su lucha.

Asimismo, los sectores populares iban descubriendo la importancia de trabajar en frente, en los sindicatos y en los asentamientos urbanos populares (frentes de defensa del pueblo) como una manera de afianzar su independencia de clase.

El sustento ideológico de esta tendencia a la autonomía, fue el marxismo, en sus diversas expresiones, que, en sus versiones más esquemáticas, llegó a convertirse en discurso aceptado como sentido común en amplios sectores populares urbanos. Generalizó la idea de la ruptura radical entre sectores populares y Estado-burguesía, pero la pretensión de cada partido de ser el único auténtico representante del pueblo, limitó al mismo tiempo su potencial de unificación para la lucha.

La renovación del pensamiento cristiano, en torno a los resultados del Concilio Vaticano II y de su aplicación a América Latina en Medellín, así como el desarrollo de las comunidades cristianas de base inspiradas en la Teología de la Liberación, constituyeron también aportes importantes para la transformación de la cultura en el mundo moderno. 
El descubrimiento de que era posible desarrollar el frente también en el nivel político, estuvo ligado a la nueva coyuntura electoral desde fines de los años 70 . Los dirigentes populares y los dirigentes políticos empezaron a reconocer que quienes militaban en otro partido no necesariamente eran "agentes del gobierno" o del "imperialismo" y que era posible unirse con otros para progresar en el "camino de la revolución", es decir para afianzar la ruptura con el Estado.

La violencia política actual, desde la ultraizquierda, proviene de aquellos que, en lugar de abrirse al frente, se encerraron más en su propia organización. Para el resto de la izquierda empieza un lento tránsito del espíritu de secta al de frente, de lo endógeno a lo exógeno. Ello es favorecido por la nueva situación del país que, desde las elecciones de 1980, obliga a los partidos a buscar alianzas, y que pone sobre el tapete la cuestión de la democracia.

Para los dirigentes populares, el cambio de actitud no es fácil. En efecto, no se trata de un cambio cualquiera de orientación. Desde la perspectiva endógena, todo era muy claro: nosotros somos los auténticos revolucionarios, los únicos militantes respetuosos de la línea correcta, mientras todos los demás - partidos y Estado- son agentes diversos del imperialismo. Pero desde la perspectiva exógena del frente, es necesario evaluar uno por uno a los demás partidos, debatir sobre puntos programáticos $\mathrm{y}$ actuar juntos, con el riesgo de perder "el perfil propio".

Además, la participación en las elecciones conduce a la necesidad de aceptar ciertas responsabilidades en diferentes niveles del Estado. En los dirigentes populares, esto es particularmente evidente cuando la Izquierda Unida gana el gobierno de muchos municipios. Se tiene entonces que conciliar con distintas instancias del Estado, se deben tomar acuerdos con los demás partidos. El esquema mental para pensar el frente era claro: unir las fuerzas 
populares para enfrentar mejor al Estado burgués y al imperialismo. En la actualidad, el esquema sigue vigente para muchos, pero la situación concreta ha cambiado: muchas veces se concilia con determinadas instancias del Estado, y existe inclusive la posibilidad real de llegar a ser gobierno. ¿Cómo se conduce esto con la proclamada autonomía de la organización popular? La respuesta es diversa y está ligada a la propuesta estratégica de cada una de las organizaciones de izquierda. Pero en todo caso, la nueva situación planteada permite comprender por qué el lenguaje sigue siendo a menudo radical, parecido al de la situación anterior, mientras la práctica se orienta más hacia respuestas en términos de negociación.

Tendrá que precisarse, entonces, qué visión tiene el dirigente popular del Estado; de qué manera concibe el protagonismo popular y su relación con el Estado; cuál es su visión del país y del problema nacional. Asimismo, ver lo que entiende por poder, por autoridad, y cuáles son para él el poder y la autoridad legítimos; de qué manera resuelve los conflictos y cómo plantea la forja del consenso; en qué condiciones acepta la violencia como legítima; qué es para él la democracia y de qué manera la incorpora a su actuar.

En la tradición andina, la relación con los españoles siempre ha sido ambivalente: una gran desconfianza mezclada con la búsqueda de sacarle todos los beneficios que se puedan mediante la adulación. En buena medida, esta actitud antigua se reproduce hoy en la relación con el Estado. Pero la posibilidad de ejercer el gobierno en distintas instancias y niveles de responsabilidad, empieza probablemente a cuestionar tal actitud en la práctica popular. La idea de la "protesta con propuesta" surgida de la lucha de los Comités del Vaso de Leche, es una de las tantas muestras de ese cambio. Queda por averiguar cuánto de la anti- 
Autoridad y democracia en la cultura popular

gua actitud permanece en los dirigentes populares dificultando su adaptación a los nuevos tiempos.

Lima, julio de 1989 


\section{Notas}

(1) El presente texto ha recibido muchos aportes, en distintos niveles, de investigadores $y$ educadores de diversas instituciones. Aunque el texto es de mi responsabilidad, es también producto de un trabajo de equipo con Maruja Boggio, Betty de Madalengoitia, Marita Palacios, Fernando Romero, Enrique Tineo.

(2) Tal resolución no necesariamente es pacífica, por lo que, en la línea de Clausewitz, asumo aquí que la guerra es una forma de hacer política. Claude Levi-Strauss, en cambio, planteaba en Las estructuras elementales del parentesco (Buenos Aires, Paidos, 1969) que, en la sociedad primitiva, la guerra era el fracaso de la alianza (considerada como base de lo político), punto de vista que fue criticado por Pierre Clastres, antropólogo francés que llamó la atención sobre la guerra como elemento constitutivo de lo político en la sociedad primitiva (llamada por él "sociedad contra el Estado"). Véase: CLASTRES, Pierre. 1980. Recherches d'anthropologie politique. Seuil. Paris.

(3) VALDERRAMA, Ricardo y ESCALANTE, Carmen. 1988. Del Tata Mallku a la Ma- ma Pacha. Sociedad y ritos en los Andes peruanos. Lima. DESCO.

(4) STERN, Steve J. 1986. Los pueblos indígenas del Perú y el desafío de la conquista española. Huamanga hasta 1640. Alianza Editorial. Madrid. Sobre las ideas expuestas aquí, véase también: ANSION, Juan. 1988. "Las condiciones de la paz vistas desde la cultura andina". En: Paz, tarea de todos, Año II, N. 6, pp. 17-22.

(5) VASQUEZ RODRIGUEZ, Chalena y VERGARA FIGUEROA, Abilio. 1988. iChayraq! Carnaval ayacuchano. CEDAP - TAREA. Ayacucho - Lima.

(6) ANSION, Juan. 1987. Desde el rincón de los muertos. El pensamiento mítico en Ayacucho. GREDES. Lima. pp. 135-140.

(7) ROSTWOROWSKI, María. 1988. Historia del Tahuantinsuyo. Instituto de Estudios Peruanos. Lima.

(8) ROSTWOROWSKI, María. 1983. Estructuras andinas del poder. Instituto de Estudios Peruanos. Lima.

(9) DUMONT, Louis. 1970. Homo hierarchicus. Ensayo sobre el sistema de castas. Madrid. Aguilar. 